\title{
Cationic Effects on the Effective Hydrogen Atom Bond Dissociation Free Energy of High Valent Manganese Imido Complexes
}

\author{
Nadia G. Léonard, a Teera Chantarojsiri,b Joseph W. Ziller, a Jenny Y. Yanga* \\ aDepartment of Chemistry, University of California, Irvine, California, 92697, United States \\ bDepartment of Chemistry and Center of Excellence for Innovation in Chemistry, Faculty of Science, Mahidol Univer- \\ sity, Bangkok, 10400, Thailand
}

\begin{abstract}
Local electric fields can alter energy landscapes to impart enhanced reactivity in enzymes and at surfaces. There has been renewed interest on their use in molecular systems, where they can be installed using charged functionalities. Manganese (V) salen nitrido complexes (salen = N,N'-ethylenebis(salicylideneaminato)) appended with a crown ether unit containing a $\mathrm{Na}^{+}(\mathbf{1}-\mathbf{N a}), \mathrm{K}^{+},(\mathbf{1}-\mathbf{K}), \mathrm{Ba}^{2+}(\mathbf{1}-\mathbf{B a}), \mathrm{Sr}^{2+}(\mathbf{1}-\mathbf{S r}), \mathrm{La}^{3+} \mathbf{( 1 - L a )}$, or $\mathrm{Eu}^{3+}$ (1-Eu) cation were investigated to experimentally demonstrate the effect of cation-induced electric fields on $\mathrm{p} K_{\mathrm{a}}, E_{1 / 2}$, and the effective bond dissociation free energy (BDFE) of $\mathrm{N}-\mathrm{H}$ bonds. The series, which includes the manganese (V) salen nitrido without a crown appended, spans 4 units of charge. Bounds for the $\mathrm{p} K_{\mathrm{a}}$ values of the transient imido complexes were determined by UV-visible and ${ }^{1} \mathrm{H}$ NMR spectroscopy. These values, together with the reduction potentials for the $\mathrm{Mn}(\mathrm{VI} / \mathrm{V})$ couple measured by cyclic voltammetry in acetonitrile, were used to calculated the N-H BDFEs of the imidos. Despite spanning $>700 \mathrm{mV}$ and $>9 \mathrm{p} K_{\mathrm{a}}$ units across the series, the hydrogen atom BDFE only spans $\sim 5 \mathrm{kcal} / \mathrm{mol}$ (between 76 and $81 \mathrm{kcal} / \mathrm{mol}$ ). These results suggest that incorporation of cationic functionalities is an effective strategy for accessing wide ranges of reduction potentials and $\mathrm{p} K_{\mathrm{a}}$ while minimally affecting BDFE, which is essential to modulating electron, proton, or hydrogen atom transfer pathways.
\end{abstract}

The activation of strong heteroatom-hydrogen $(\mathrm{X}-\mathrm{H})$ bonds using high valent metal oxidos or nitridos as hydrogen atom acceptors is an robust area of bio-inspired reaction chemistry. ${ }^{1-4}$ The free energy of these reactions is dependent on the hydrogen-atom bond dissociation free energies (BDFE) for the reactants and products. BDFE values are comprised of both the $\mathrm{p} K_{\mathrm{a}}$ and redox potential $\left(E_{1 / 2}\right)$ according to eq. 1 (Chart 1 ). ${ }^{5-7}$ Exergonic reactivity with metal oxidos or nitridos requires the BDFE values for the resultant hydroxido or imido bonds to exceed that of the targeted X$\mathrm{H}$ bond. However, the relative contributions of $\mathrm{p} K_{\mathrm{a}}$ and $E_{1 / 2}$ to the BDFE are also critical for steering reactivity. 8,9 The difference in reduction potential and $\mathrm{p} K_{\mathrm{a}}$ between the donor and accepter ( $\Delta E_{1 / 2}$ and $\Delta \mathrm{p} K_{\mathrm{a}}$, respectively) governs the most favorable reaction pathway for either proton or electron transfer, or concerted hydrogen atom transfer (HAT). For example, Green and co-workers reported that cytochrome $\mathrm{P} 450$ activates strong $\mathrm{C}-\mathrm{H}$ bonds at a mild potential due to an unusually basic iron(IV) oxido species, thus lowering the driving force for unfavorable single-electron redox events. ${ }^{11}$ More broadly, the most favorable reaction pathways based on $\Delta E_{1 / 2}$ and $\Delta \mathrm{p} K_{\mathrm{a}}$ can be mapped onto proton-coupled electron transfer (PCET) zone diagrams, as described by Glover, Hammerström, and co-workers. ${ }^{11}$ In some cases, the rate of HAT correlates more strongly with $\Delta E_{1 / 2}$ or $\Delta \mathrm{p} K_{\mathrm{a}}$ than $\Delta \mathrm{G}(\mathrm{H} \cdot),{ }^{12-14}$ deviating from the Bell-Evans-Polanyi principle that overall free energy governs kinetic reactivity. ${ }^{15,16}$ These examples illustrate a route to achieving kinetic selectivity for the cleavage of stronger $\mathrm{X}$ $\mathrm{H}$ bonds in the presence of weaker bonds. Thus,
Chart 1. (left) Manganese nitride complexes and (right) thermodynamic properties investigated in this study.

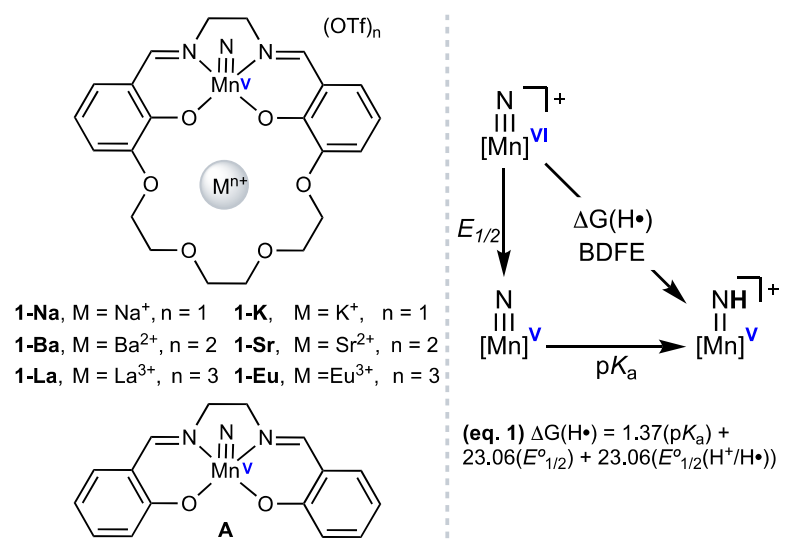

understanding how synthetic variations modify the reduction potential, $\mathrm{p} K_{\mathrm{a}}$, and consequent BDFE is critical for controlling the thermodynamics and kinetics for HAT reactions.

Most studies have used inductive effects (i.e. electrondonating and withdrawing functionalities) to modulate these thermodynamic quantities, leading to modest changes. ${ }^{17}$ An alternative approach is to use the secondary coordination sphere to tune these properties. Borovik and coworkers demonstrated basicity controlled HAT to a manganese-oxido, where the $\mathrm{p} K_{\mathrm{a}}$ of the resulting hydroxide was 
modulated by hydrogen-bond donation from the amide ligand (Figure $1 \mathrm{a}$, left). ${ }^{18}$

The use of electrostatic interactions to control reactivity has inspired the design of a growing number of synthetic molecular complexes that incorporate charged functionalities. ${ }^{19-45}$ However, very few experimental studies explicitly examine the secondary effect of charge. A rare example from Tolman and co-workers investigated pincer coordinated $\mathrm{Cu}(\mathrm{II})$-hydroxide complexes (Figure $1 \mathrm{a}$, right). ${ }^{46}$ They reported that incorporation of sulfonate or trimethylammonium substituents expands the range of the $\mathrm{Cu}(\mathrm{III} / \mathrm{II})$ reduction potential $\left(E_{1 / 2}\right)$ by $275 \mathrm{mV}$. Despite the change in $E_{1 / 2}$, the bond dissociation energies of the respective $\mathrm{Cu}(\mathrm{II})$-aqua species remained relatively constant while the kinetics of hydrogen atom transfer to the $\mathrm{Cu}($ III)-hydroxide varied. Tolman and coworkers attribute the varying kinetic rates to steric contributions of the counterions in addition to possible electrostatic effects. However, direct correlations between changes in thermochemical parameters and electrostatic effects at molecular complexes has been minimally explored. ${ }^{47-50}$

In this study, we report the profound effect of a proximal mono-, di-, and tri-cation on high-valent $\mathrm{Mn}$ nitrido complexes and the hydrogen atom BDFEs of their associated imidos. The salen-crown framework provides a unique platform for isolating the effect of cationic charge on the metal center (Chart 1). The salen macrocyclic ligand supports high-valent metal ions. Non-redox active cations of varying charge are easily inserted into the crown cavity which significantly modifies the electric field potential around the redox active metal. ${ }^{51}$ Our previous investigation of $\mathrm{Mn}(\mathrm{V})$ salen nitrido complexes (1-Na, 1-K, 1-Ba, 1-Sr)

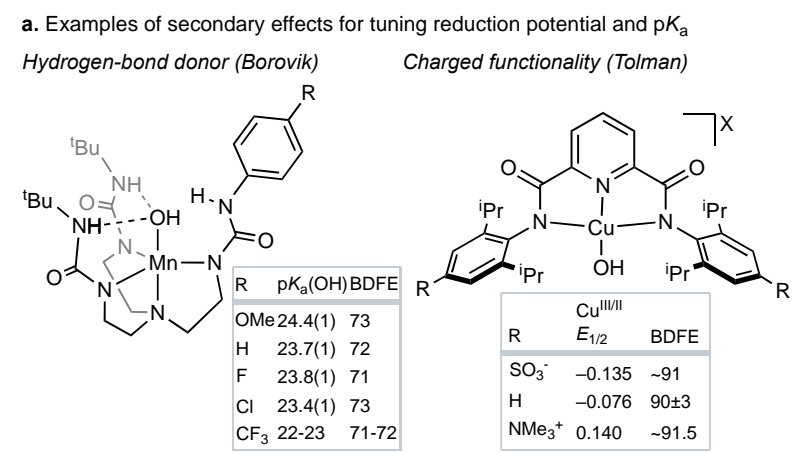

b. Activation of salen manganese nitrides

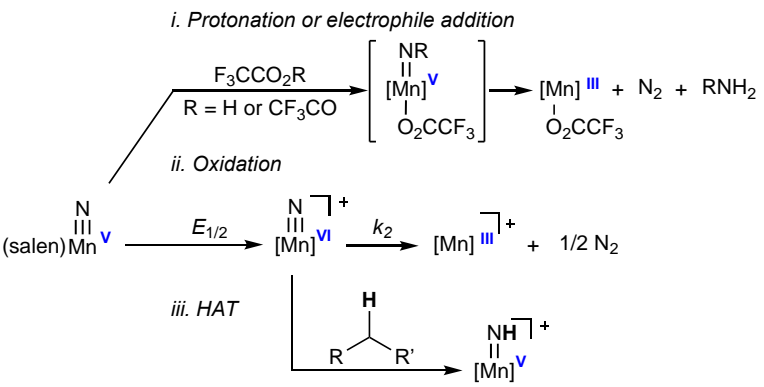

Figure 1. (a) Hydrogen-bond donors and charged substituents on ligands tune $E_{1 / 2}$ or p $K_{\mathrm{a}}$ in metal-hydroxides. (refs 17 and 45) (b) Examples of activation of salen manganese nitrides, some of which involve formation of intermediate metal imidos (i. ref 65 ; ii. refs 53 and 82; iii. ref 96 and this work.). with bound alkali and alkaline earth metals showed that an increase of cationic charge at the complexes resulted in anodic shifts of over $400 \mathrm{mV}$ of the $\mathrm{Mn}(\mathrm{VI} / \mathrm{V})$ reduction potential (Table 1). ${ }^{52}$ To expand on these studies, we synthesized two derivatives with +3 cations, so that our data set spans four different units of charge. We also experimentally determine the impact of charge on $\mathrm{C}-\mathrm{H}$ bond activation.

Manganese nitrido complexes were selected for this study due to their utility in a variety of catalytic and stoichiometric reactions, many of which involve the formation of intermediate imidos (Figure 1b.). ${ }^{53-66}$ Lau and coworkers previously reported salen manganese nitrido complexes that were activated for stoichiometric aziridination of alkenes following protonation with a Brønsted acid or addition of electrophiles. ${ }^{67-69}$ Chirik and coworkers demonstrated proton-coupled electron transfer (PCET) at salen manganese nitrido complexes to form ammonia through either photodriven ${ }^{70,71}$ or thermal 72 pathways. Although the bond dissociation free energies (BDFEs) at transition metal imidos are central in catalytic nitrogen cycles ${ }^{73-78}$ and $\mathrm{C}-\mathrm{H}$ activation, ${ }^{79-84}$ few BDFE values have been measured compared to isoelectronic metal oxido analogues.

Following a modification of the previously reported procedure, 1-La and 1-Eu were obtained in quantitative and $94 \%$ yield, respectively (see SI for details). The ${ }^{1} \mathrm{H}$ NMR of 1-La exhibited sharp diamagnetic resonances and the number of peaks was consistent with $\mathrm{C}_{2 \mathrm{~V}}$ symmetry (Figure S27). The ${ }^{1} \mathrm{H}$ NMR of $\mathbf{1 - E u}$ exhibited paramagnetically shifted resonances due to the unpaired spin of the $\mathrm{Eu}^{3+}$ cation, however the number of observed peaks was also consistent with $\mathrm{C}_{2 \mathrm{v}}$ symmetry (Figure S29). Single crystals suitable for X-ray diffraction of 1-La (Figure 2a.) and 1-Eu (Figure S31) were obtained from concentrated acetonitrile solutions. In the solid state, both 1-La and 1-Eu show three inner sphere triflate anions, one of which is coordinated $\kappa^{2} O, O^{\prime}$ to the $\mathrm{La}^{3+}$ cation in 1-La.

The electrochemical properties of 1-La and 1-Eu were measured in acetonitrile using cyclic voltammetry (see SI for full experimental details). We previously described the bimolecular coupling of the oxidized Mn(VI) species to form two equivalents of the corresponding Mn(III) complex and $\mathrm{N}_{2}$, or an EC mechanism (electron transfer followed by a chemical step) (Figure 1b.ii). ${ }^{52,56}$ In the prior study with the

Table 1. Summary of Thermodynamic Parameters

\begin{tabular}{l|l|l|l}
\hline Complex & $E_{1 / 2^{\mathrm{c}}}$ & $\mathrm{p} K_{\mathrm{a}}{ }^{\mathrm{d}}$ & $\mathrm{N}-\mathbf{H} \mathrm{BDFE}$ \\
\hline $\mathbf{A}^{\mathrm{a}}$ & 0.43 & $8.0-9.4$ & $76-78$ \\
\hline $\mathbf{1 - N a}$ & 0.59 & $6.2-8.0$ & $77-80$ \\
\hline $\mathbf{1}^{\mathrm{a}} \mathbf{K}^{\mathrm{a}}$ & 0.62 & $6.2-8.0$ & $78-80$ \\
\hline $\mathbf{1 - B a}$ & 0.80 & $0.2-2.6$ & $74-77$ \\
\hline $\mathbf{1 - S r ^ { \mathrm { a } }}$ & 0.88 & $0.2-2.6$ & $75-79$ \\
$\mathbf{1}^{\mathrm{a}} \mathbf{L a}^{\mathrm{b}}$ & 1.02 & $<0.2$ & $<79$ \\
\hline $\mathbf{1 - E u}^{\mathrm{b}}$ & 1.13 & $<0.2$ & $<81$ \\
\hline
\end{tabular}

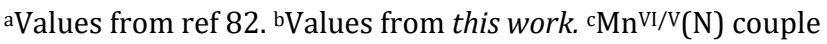
vs. $\mathrm{Fe}\left(\mathrm{C}_{5} \mathrm{H}_{5}\right)_{2}+/ 0$ in MeCN. dValues from protonation of nitride complexes in $\mathrm{MeCN}-d_{3}$ at $20{ }^{\circ} \mathrm{C}$ as determined by ${ }^{1} \mathrm{H}$ NMR. eValues in $\mathrm{kcal} / \mathrm{mol}$, calculated from experimentally measured $E_{1 / 2}$ and $\mathrm{p} K_{\mathrm{a}}$ data according to equation 1. 

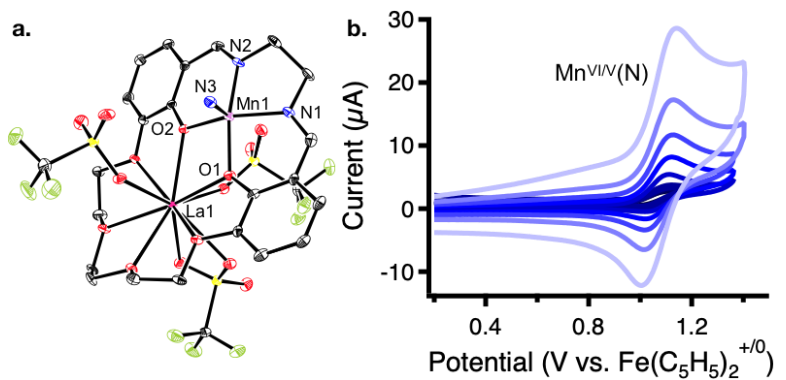

Figure 2. a. Solid state molecular structure of 1-La at $50 \%$ probability ellipsoids. Hydrogen atoms were omitted for clarity. Selected bond metrics: Mn1-N3, 1.524(2); Mn1La1, 3.6220(6). See SI for full bond lengths and angles. $b$. Scan-rate dependent cyclic voltammetry of 1-La (2 mM) showing $\mathrm{Mn}{ }^{\mathrm{VI} / \mathrm{V}}$ oxidation event with scan rates ranging from $10 \mathrm{mV} / \mathrm{s}$ to $2500 \mathrm{mV} / \mathrm{s}$ in $\mathrm{CH}_{3} \mathrm{CN}$ and $0.2 \mathrm{M} \mathrm{TBAPF}_{6}$ electrolyte.

mono- and di-cationic nitrido complexes, an increase in charge corresponded to a slower rate of bimolecular coupling. Consistent with this trend there is no evidence of bimolecular coupling upon oxidation of 1-La to Mn(VI) even at slow scan rates $(10 \mathrm{mV} / \mathrm{s})$ (Figure $\mathrm{S} 17)$. The redox event is reversible and there is no reduction event corresponding to the $\mathrm{Mn}$ (III/II) couple at more negative potentials, which would be the expected product of bimolecular coupling. The scan-rate dependent cyclic voltammetry was collected for 1-La (Figure 2b.). The current increases linearly with the square root of the scan rate, indicating electron transfer is under diffusion control (Figure S18).

Complex 1-Eu does not exhibit a strictly reversible oxidation event corresponding to the $\mathrm{Mn}(\mathrm{VI} / \mathrm{V})$ redox couple (Figure S19); the cathodic wave is smaller than the anodic wave. Although analytically pure 1-Eu is used for cyclic voltammetry, there is evidence that upon oxidation adventitious $\mathrm{Na}^{+}$ions (ionic radius of $102 \mathrm{pm}$ ) displaces the europium (III) ion due to the latter's poor fit (ionic radius of 94.7 $\mathrm{pm}$ ) in the crown. ${ }^{85}$ There is no evidence of any contamination by 1-Na prior to oxidation by elemental analysis. Additionally, the 1-Na oxidation peak is not observed in the initial oxidative scan. However, after several oxidation cycles, an additional cathodic redox feature appears at $\sim 0.6 \mathrm{~V}$ (vs. $\left[\mathrm{Fe}\left(\mathrm{C}_{5} \mathrm{H}_{5}\right)_{2}\right]^{+/ 0}$ ) (Figure S21), which matches the oxidation potential of the $\mathrm{Mn}(\mathrm{V})$ nitrido with $\mathrm{Na}^{+}$in the crown cavity. Based on the oxidation event observed for 1-Eu, we estimate an $E_{1 / 2}$ value of $\sim 1.13 \mathrm{~V}$ for 1-Eu.

The $E_{1 / 2}$ values for the $\mathrm{Mn}(\mathrm{VI} / \mathrm{V})$ reduction potential of $1.02 \mathrm{~V}$ and $\sim 1.13 \mathrm{~V}$ (vs. $\left[\mathrm{Fe}\left(\mathrm{C}_{5} \mathrm{H}_{5}\right)_{2}\right]^{+/ 0}$ ) for 1-La and 1-Eu, respectively, corresponds to a shift of 600 and $730 \mathrm{mV}$ more positive than that of the non-crown (salen) MnN (A). These values correspond to 14 and $16 \mathrm{kcal} / \mathrm{mol}$ changes, respectively, in the $E_{1 / 2}$ contributions to the N-H BDFE (eq 1 in Chart 1 and Figure 3).

We investigated the protonation of the manganese(V) nitrido complexes in order to determine the $\mathrm{p} K_{\mathrm{a}}$ values and calculate the BDFE of the imido as a function of overall cationic charge (Figure 1b.i). The direct detection and isolation of electrophilic transition metal parent imido complexes is challenging because of accessible coupling, disproportionation, and nitrene transfer pathways. ${ }^{86-90}$ Acid titration experiments conducted at room temperature or $-35^{\circ} \mathrm{C}$ in acetonitrile and were monitored by UV-vis spectroscopy by observing changes to two absorption bands associated with the manganese nitrido at $\sim 380$ and $\sim 600 \mathrm{~nm}$. No spectral features corresponding to a putative imido were observed by UV-vis.

Lau and coworkers previously discussed the instability of the imido formed following protonation of the nitrido. ${ }^{68}$ They postulate that, following protonation of the nitrido, 2 equiv. of the resulting imido complex couple to form a manganese(III) $\mu$-diazene species, which rapidly decomposes to give the final $\mathrm{Mn}(\mathrm{III}), \mathrm{N}_{2}$, and $\mathrm{NH}_{3}$ (Figure 1.b.i). Indeed, in our studies the UV-vis spectrum at the endpoint of acid titration corresponded to that of the Mn(III) complexes.

In an effort to observe the imido, we synthesized the ${ }^{15} \mathrm{~N}$-labeled nitrido complex, 1-Ba( $\left({ }^{15} \mathbf{N}\right)$. Protonation of 1$\mathbf{B a}\left({ }^{15} \mathrm{~N}\right)$ with 1 equiv. $\left[\mathrm{H}\left(\mathrm{OEt}_{2}\right)_{2}\right]\left[\mathrm{BF}_{4}\right]$ in acetonitrile- $d_{3}$ was performed in a J-Young tube and tracked by ${ }^{1} \mathrm{H}$ and ${ }^{15} \mathrm{~N}$ NMR at $-30 \stackrel{\circ}{\circ}$. Only resonances corresponding to the starting material and Mn(III) product were observed. Additionally, analysis of the gas headspace following protonation of 1$\mathbf{B a}\left({ }^{15} \mathbf{N}\right)$ showed evolution of ${ }^{14} \mathrm{~N}^{15} \mathrm{~N}$ and ${ }^{15} \mathrm{~N}_{2}$, further supporting the coupling pathway postulated by Lau. It is possible that instead of protonating on the nitrido, nucleophilic attack at the imine of the salen could occur.91-93 Alternatively, protonation of the crown ether could result in displacement of the bound cation. ${ }^{94-96}$ However, protonation at either of these sites is unlikely, as there is quantitative recovery of the of the manganese(III) complex following protonation, indicating the reactivity proceeds as shown in Figure 1.b.i.

The instability of the manganese salen imidos precluded accurate establishment of an equilibrium following protonation of the nitrido. Therefore, we determined bounds for the $\mathrm{p} K_{\mathrm{a}}$ values by tracking protonation using ${ }^{1} \mathrm{H}$ NMR in acetonitrile- $d_{3}$ at room temperature. Protonation of the Mn(V)N with acids of known $\mathrm{p} K_{\mathrm{a}}$ values (see SI for full experimental details) resulted in effective bracketing of the $\mathrm{p} K_{\mathrm{a}}$ values for the imido intermediates. Notably, the $\mathrm{p} K_{\mathrm{a}}$ values span $\sim 9$ units, with the basicity of the $M n(V)$ nitrido decreasing with increasing charge of the bound cation. A linear correlation between the $\mathrm{Mn}(\mathrm{VI} / \mathrm{V})$ reduction potential and $\mathrm{p} K_{\mathrm{a}}$ was also observed (Figure 3 ), indicating that a positive shift in reduction potential is largely compensated by acidification of the imido.

The BDFEs for the imido $\mathrm{N}-\mathrm{H}$ bonds were then calculated according to the thermodynamic relation depicted in the square scheme in Chart 1 and equation 1 . These values are also tabulated in Table 1 . The change in $\mathrm{p} K_{\mathrm{a}}$ and positive shift in reduction potential serve to maintain a relatively constant BDFE across the series, encompassing four different overall charges. Although determination of $\mathrm{N}-\mathrm{H}$ bond strengths is challenging due to the reactive nature of the intermediate imido, understanding these values is essential to predicting reactivity. In a recent computational study from Cundari and coworkers on these crown-appended manganese nitrido salen complexes, they determined that increase in charge at the bound cation resulted in an increase in $\mathrm{N}-\mathrm{H}$ BDFE. ${ }^{97}$ Further, an increase in charge of the cation was correlated to lowering of the free barrier energy for hydrogen atom transfer (HAT) from methane, thus indicating that this process should be kinetically facilitated by the presence of bound cation. Therefore, we explored the hydrogen atom 


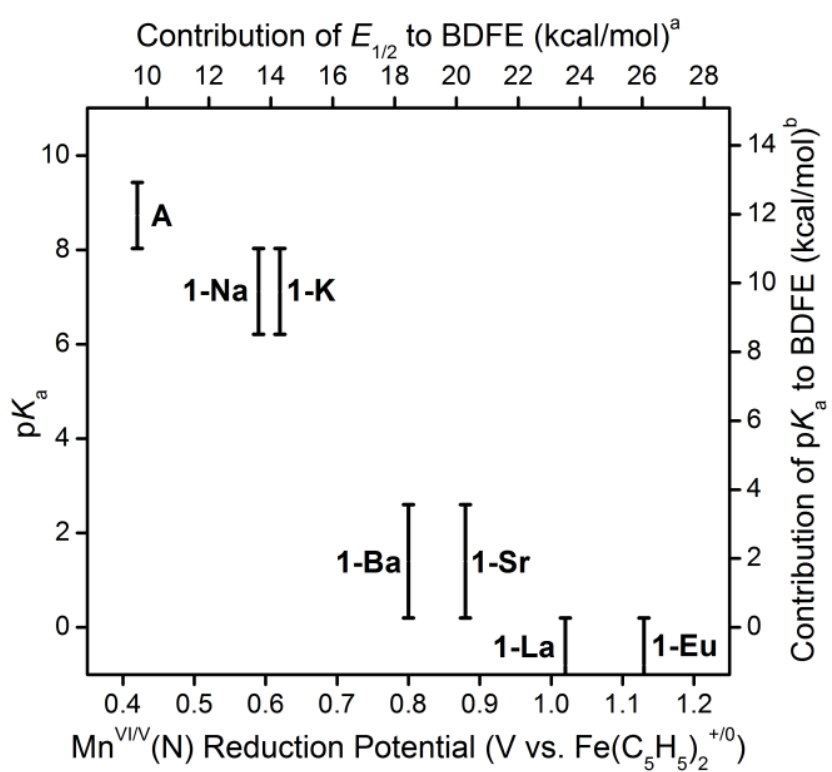

Figure 3. Plot showing compensatory relationship between reduction potential and $\mathrm{p} K_{\mathrm{a}}$ for complexes with incorporation of cationic charge, leading to similar BDFE values across the series. axis values calculated as $23.06\left(E_{1 / 2}\right)$ as shown in equation $1 .{ }^{b}$ Axis values calculated as $1.37\left(\mathrm{p} K_{\mathrm{a}}\right)$ as shown in equation 1 .

abstraction (HAA) reactivity of the Mn(VI) complexes with a hydrogen atom donor, 9,10-dihydroanthracene (DHA, BDFE $($ DMSO $)=76 \mathrm{kcal} / \mathrm{mol})^{17}$ (Figure 4). Through UV-visible spectroelectrochemical experiments as well as chemical oxidation, we determined that hydrogen atom transfer (HAT) reactivity was enhanced in the presence of the intramolecular cation.

UV-visible spectroelectrochemistry was used to monitor the reactivity of complexes $\mathbf{A}$ and 1-Ba in the presence of 100 equiv. DHA. Upon oxidizing $\mathbf{A}$ to the $\mathrm{Mn}(\mathrm{VI})$ species, only spectral changes that correspond to formation of Mn(III) were observed (Figure S13). Recovery of the solution following bulk electrolysis and analysis by ${ }^{1} \mathrm{H}$ NMR spectroscopy showed no evidence for formation of anthracene, the expected product of hydrogen atom abstraction. For 1-Ba, however, absorption bands corresponding to

Scheme 1. Reaction of manganese complexes with DHA following oxidation.

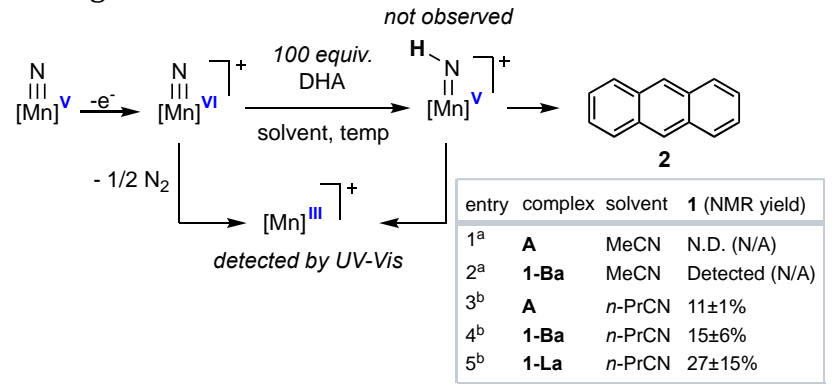

aReaction performed by spectroelectrochemical UV-Vis in $\mathrm{MeCN}$ at $20^{\circ} \mathrm{C}$. bReaction performed by chemical oxidation with 1 equiv. tris(2,4-dibromophenyl)aminium hexachloroantimonate (Magic Green) in $n$-PrCN at $-40{ }^{\circ} \mathrm{C}$. See SI for full experimental details. anthracene (340-380 $\mathrm{nm}$ ) were observed to increase in intensity during electrolysis (Figure S14). Analysis of the recovered solution following electrolysis by ${ }^{1} \mathrm{H}$ NMR spectroscopy exhibited peaks corresponding to anthracene. Attempts to perform the spectroelectrochemical electrolysis of solutions of 1-La in the presence of 100 equivalents of DHA and monitoring by UV-Vis were unsuccessful. The positive potential required to oxidize 1-La resulted in direct oxidation of DHA, resulting in unreliable determination of whether 1-La was reacting with DHA directly. Therefore, we elected to perform the chemical oxidation of A, 1-Ba, and 1-La with tris(2,4-dibromophenyl)aminium hexachloroantimonate (Magic Green) under an inert atmosphere in $n$ $\mathrm{PrCN}$ at $-40{ }^{\circ} \mathrm{C}$. Following in situ generation of the $\mathrm{Mn}(\mathrm{VI})$ nitrido and consumption of Magic Green, 10 equiv. of DHA were subsequently added and the reaction was allowed to stir at $-40{ }^{\circ} \mathrm{C}$ until no further reaction was observed. Analysis of the products by ${ }^{1} \mathrm{H}$ NMR was used to quantify the yield of anthracene (2) for each manganese complex (Scheme 1, inset table, Figure S15). Results of the chemical oxidation were variable due to issues with complete formation of the $\mathrm{Mn}(\mathrm{VI})$ intermediate prior to addition of 9,10-dihydroanthracene. However, the addition of cationic charge did have a slightly positive effect on $\mathrm{C}-\mathrm{H}$ activation. The hydrogen atom abstraction exhibited by 1-Ba and 1-La may be due to the inhibition of bimolecular coupling following oxidation to the $\mathrm{Mn}(\mathrm{VI})$ due to charge. ${ }^{52}$ However, additional electrostatic interactions facilitating HAT cannot be ruled out.

Protonation and hydrogen atom transfer reactions were explored at a series of Mn-nitrido salen complexes with appended crown-bound cations. The effect of electrostatics imparted by the cation were investigated for their reactivity toward proton and electron transfer. Our results established BDFEs for the manganese imido $\mathrm{N}-\mathrm{H}$ bonds and demonstrated reactivity with a hydrogen atom donor, DHA, where incorporation of bound cation facilitated HAT. Our findings demonstrate the utility of electric fields for tuning reduction potential, $\mathrm{p} K_{\mathrm{a}}$, and $\mathrm{BDFE}$, while also differentially affecting hydrogen atom transfer. Future work will focus on understanding electrostatic effects for controlling different pathways for proton and electron transfer as well as $\mathrm{C}-\mathrm{H}$ activation.

\section{ASSOCIATED CONTENT}

\section{Supporting Information}

The Supporting Information is available free of charge on the ACS Publications website.

Experimental procedures and spectroscopic data (PDF)

Crystallographic data (CIF)

\section{AUTHOR INFORMATION}

\section{Corresponding Author}

*E-mail: j.yang@uci.edu

ORCID

Nadia G. Léonard: 0000-0002-0949-5471

Teera Chantarojsiri: 0000-0002-4951-9503 
Joseph W. Ziller: 0000-0001-7404-950X

\section{Jenny Y. Yang: 0000-0002-9680-8260}

\section{Author Contributions}

The manuscript was written through contributions of all authors. / All authors have given approval to the final version of the manuscript. / $\$$ These authors contributed equally. (match statement to author names with a symbol)

\section{Funding Sources}

TC was supported by NSF Award \#15554744 and NGL by NIH 3R01GM134047-02S1. NGL would also like to acknowledge support from the UC Presidential Postdoctoral Fellowship Program. J.Y.Y. also acknowledges support as a Sloan Foundation Fellow, a Canadian Institute for Advanced Research (CIFAR) Azrieli Global Scholar in the Bio-Inspired Solar Energy Program, and a Camille Dreyfus Teacher Scholar.

\section{ACKNOWLEDGMENT}

We thank J. L. Lee in Prof. Borovik's group (UCI) for assistance in collecting EPR spectroscopy data. We also thank Dr. Felix Grun (UCI) for assistance with collecting mass spectrometry data.

\section{REFERENCES}

(1) Smith, J. M. Reactive Transition Metal Nitride Complexes. Prog. Inorg. Chem. 2014, 58, 417-470. https://doi.org/10.1002/9781118792797.ch06.

(2) Sacramento, J. J. D.; Goldberg, D. P. Factors Affecting Hydrogen Atom Transfer Reactivity of Metal-Oxo Porphyrinoid Complexes. Acc. Chem. Res. 2018, 51 (11), 2641-2652. https://doi.org/10.1021/acs.accounts.8b00414.

(3) Gunay, A.; Theopold, K. H. C-H Bond Activations by Metal Oxo Compounds. Chem. Rev. 2010, 110 (2), 1060-1081. https://doi.org/10.1021/cr900269x.

(4) Larson, V. A.; Battistella, B.; Ray, K.; Lehnert, N.; Nam, W. Iron and Manganese Oxo Complexes, Oxo Wall and Beyond. Nat. Rev. Chem. 2020, 4 (8), 404-419. https://doi.org/10.1038/s41570-020-0197-9.

(5) Wiberg, K. B.; Foster, G. The Stereochemistry of the Chromic Acid Oxidation of Tertiary Hydrogens1. J. Am. Chem. Soc. 1961, 83 (2), 423-429. https://doi.org/10.1021/ja01463a041.

(6) Breslow, R.; Balasubramanian, K. $\mathrm{p} K_{\mathrm{a}}$ of Triphenylcyclopropene. Electrochemical Determination of an Inaccessible Equilibrium Constant. J. Am. Chem. Soc. 1969, 91 (18), 5182-5183. https://doi.org/10.1021/ja01046a055.

(7) Bordwell, F. G.; Cheng, J. Pei.; Harrelson, J. A. Homolytic Bond Dissociation Energies in Solution from Equilibrium Acidity and Electrochemical Data. J. Am. Chem. Soc. 1988, 110 (4), 12291231. https://doi.org/10.1021/ja00212a035.

(8) Hammes-Schiffer, S. Proton-Coupled Electron Transfer: Moving Together and Charging Forward. J. Am. Chem. Soc. 2015, 137 (28), 8860-8871. https://doi.org/10.1021/jacs.5b04087.

(9) Darcy, J. W.; Koronkiewicz, B.; Parada, G. A.; Mayer, J. M. A Continuum of Proton-Coupled Electron Transfer Reactivity. Acc. Chem. Res. 2018, 51 (10), 2391-2399. https://doi.org/10.1021/acs.accounts.8b00319.

(10) Tyburski, R.; Liu, T.; Glover, S. D.; Hammarström, L. Proton-Coupled Electron Transfer Guidelines, Fair and Square. J. Am. Chem. Soc. 2021, 143, 560-576. https://doi.org/10.1021/jacs.0c09106.

(11) Yosca, T. H.; Rittle, J.; Krest, C. M.; Onderko, E. L.; Silakov, A.; Calixto, J. C.; Behan, R. K.; Green, M. T. Iron(IV)Hydroxide PKa and the Role of Thiolate Ligation in $\mathrm{C}-\mathrm{H}$ Bond Activation by Cytochrome P450. Science 2013, 342 (6160), 825-829. https://doi.org/10.1126/science.1244373.
(12) Goetz, M. K.; Anderson, J. S. Experimental Evidence for PKa-Driven Asynchronicity in C-H Activation by a Terminal Co(III)-Oxo Complex. J. Am. Chem. Soc. 2019, 141 (9), 4051-4062. https://doi.org/10.1021/jacs.8b13490.

(13) Gao, H.; Groves, J. T. Fast Hydrogen Atom Abstraction by a Hydroxo Iron(III) Porphyrazine. J. Am. Chem. Soc. 2017, 139 (11), 3938-3941. https://doi.org/10.1021/jacs.6b13091.

(14) Barman, S. K.; Yang, M.-Y.; Parsell, T. H.; Green, M. T.; Borovik, A. S. Semiempirical Method for Examining Asynchronicity in Metal-Oxido-Mediated C-H Bond Activation. PNAS 2021, 118 (36). https://doi.org/10.1073/pnas.2108648118.

(15) Bell, R. P.; Hinshelwood, C. N. The Theory of Reactions Involving Proton Transfers. Proc. Royal Soc. A - Mathematical and

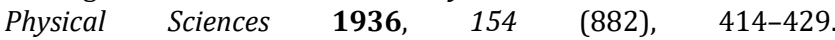
https://doi.org/10.1098/rspa.1936.0060.

(16) Evans, M. G.; Polanyi, M. Inertia and Driving Force of Chemical Reactions. Trans. Faraday Soc. 1938, 34 (0), 11-24. https://doi.org/10.1039/TF9383400011.

(17) Warren, J. J.; Tronic, T. A.; Mayer, J. M. Thermochemistry of Proton-Coupled Electron Transfer Reagents and Its Implications. Chem. Rev. 2010, 110 (12), 6961-7001. https://doi.org/10.1021/cr100085k.

(18) Barman, S. K.; Jones, J. R.; Sun, C.; Hill, E. A.; Ziller, J. W.; Borovik, A. S. Regulating the Basicity of Metal-Oxido Complexes with a Single Hydrogen Bond and Its Effect on C-H Bond Cleavage. J. Am. Chem. Soc. 2019, 141 (28), 11142-11150. https://doi.org/10.1021/jacs.9b03688.

(19) Bell, S. R.; Groves, J. T. A Highly Reactive P450 Model Compound I. J. Am. Chem. Soc. 2009, 131 (28), 9640-9641. https://doi.org/10.1021/ja903394s.

(20) Lavallo, V.; Wright II, J. H.; Tham, F. S.; Quinlivan, S. Perhalogenated Carba-Closo-Dodecaborate Anions as Ligand Substituents: Applications in Gold Catalysis. Angew. Chem. Int. Ed. 2013, $52 \quad$ (11), 3172-3176. https://doi.org/10.1002/anie.201209107.

(21) Chan, A. L.; Estrada, J.; Kefalidis, C. E.; Lavallo, V. Changing the Charge: Electrostatic Effects in Pd-Catalyzed Cross-Coupling. Organometallics 2016, 35 (19), 3257-3260. https://doi.org/10.1021/acs.organomet.6b00622.

(22) Grajeda, J.; Kita, M. R.; Gregor, L. C.; White, P. S.; Miller, A. J. M. Diverse Cation-Promoted Reactivity of Iridium Carbonyl Pincer-Crown Ether Complexes. Organometallics 2016, 35 (3), 306316. https://doi.org/10.1021/acs.organomet.5b00786.

(23) Azcarate, I.; Costentin, C.; Robert, M.; Savéant, J.-M. Through-Space Charge Interaction Substituent Effects in Molecular Catalysis Leading to the Design of the Most Efficient Catalyst of $\mathrm{CO}_{2}$-to-CO Electrochemical Conversion. J. Am. Chem. Soc. 2016, 138 (51), 16639-16644. https://doi.org/10.1021/jacs.6b07014.

(24) Shao, H.; Muduli, S. K.; Tran, P. D.; Soo, H. S. Enhancing Electrocatalytic Hydrogen Evolution by Nickel Salicylaldimine Complexes with Alkali Metal Cations in Aqueous Media. Chem. Commun. 2016, 52 (14), 2948-2951. https://doi.org/10.1039/C5CC09456A.

(25) Lau, V. M.; Pfalzgraff, W. C.; Markland, T. E.; Kanan, M. W. Electrostatic Control of Regioselectivity in Au(I)-Catalyzed Hydroarylation. J. Am. Chem. Soc. 2017, 139 (11), 4035-4041. https://doi.org/10.1021/jacs.6b11971.

(26) Davis, H. J.; Phipps, R. J. Harnessing Non-Covalent Interactions to Exert Control over Regioselectivity and Site-Selectivity in Catalytic Reactions. Chem. Sci. 2017, 8 (2), 864-877. https://doi.org/10.1039/C6SC04157D.

(27) Chattopadhyay, B.; Dannatt, J. E.; Andujar-De Sanctis, I. L.; Gore, K. A.; Maleczka, R. E.; Singleton, D. A.; Smith, M. R. Ir-Catalyzed Ortho-Borylation of Phenols Directed by Substrate-Ligand Electrostatic Interactions: A Combined Experimental/in Silico Strategy for Optimizing Weak Interactions. J. Am. Chem. Soc. 2017, 139 (23), 7864-7871. https://doi.org/10.1021/jacs.7b02232.

(28) Burns, K. T.; Marks, W. R.; Cheung, P. M.; Seda, T.; Zakharov, L. N.; Gilbertson, J. D. Uncoupled Redox-Inactive Lewis Acids in 
the Secondary Coordination Sphere Entice Ligand-Based Nitrite Reduction. Inorg. Chem. 2018, 57 (16), 9601-9610. https://doi.org/10.1021/acs.inorgchem.8b00032.

(29) Sha, S.-C.; Tcyrulnikov, S.; Li, M.; Hu, B.; Fu, Y.; Kozlowski, M. C.; Walsh, P. J. Cation- $\pi$ Interactions in the Benzylic Arylation of Toluenes with Bimetallic Catalysts. J. Am. Chem. Soc. 2018, 140 (39), 12415-12423. https://doi.org/10.1021/jacs.8b05143.

(30) Batuecas, M.; Luo, J.; Gergelitsová, I.; Krämer, K.; Whitaker, D.; Vitorica-Yrezabal, I. J.; Larrosa, I. Catalytic Asymmetric C-H Arylation of ( $\eta^{6}$-Arene)Chromium Complexes: Facile Access to Planar-Chiral Phosphines. ACS Catal. 2019, 9 (6), 5268-5278. https://doi.org/10.1021/acscatal.9b00918.

(31) Yang, L.; Uemura, N.; Nakao, Y. Meta-Selective C-H Borylation of Benzamides and Pyridines by an Iridium-Lewis Acid Bifunctional Catalyst. J. Am. Chem. Soc. 2019, 141 (19), 7972-7979. https://doi.org/10.1021/jacs.9b03138.

(32) Montero Bastidas, J. R.; Oleskey, T. J.; Miller, S. L.; Smith, M. R.; Maleczka, R. E. Para-Selective, Iridium-Catalyzed C-H Borylations of Sulfated Phenols, Benzyl Alcohols, and Anilines Directed by Ion-Pair Electrostatic Interactions. J. Am. Chem. Soc. 2019, 141 (39), 15483-15487. https://doi.org/10.1021/jacs.9b08464.

(33) Mihai, M. T.; Williams, B. D.; Phipps, R. J. Para-Selective $\mathrm{C}-\mathrm{H}$ Borylation of Common Arene Building Blocks Enabled by IonPairing with a Bulky Countercation. J. Am. Chem. Soc. 2019, 141 (39), 15477-15482. https://doi.org/10.1021/jacs.9b07267.

(34) Olivo, G.; Capocasa, G.; Lanzalunga, O.; Stefano, S. D.; Costas, M. Enzyme-like Substrate-Selectivity in C-H Oxidation Enabled by Recognition. Chem. Commun. 2019, 55 (7), 917-920. https://doi.org/10.1039/C8CC09328H.

(35) Erickson, J. D.; Preston, A. Z.; Linehan, J. C.; Wiedner, E. S. Enhanced Hydrogenation of Carbon Dioxide to Methanol by a Ruthenium Complex with a Charged Outer-Coordination Sphere. ACS Catal. 2020, $10 \quad$ (13), https://doi.org/10.1021/acscatal.0c02268.

(36) Oswald, V. F.; Lee, J. L.; Biswas, S.; Weitz, A. C.; Mittra, K.; Fan, R.; Li, J.; Zhao, J.; Hu, M. Y.; Alp, E. E.; Bominaar, E. L.; Guo, Y.; Green, M. T.; Hendrich, M. P.; Borovik, A. S. Effects of Noncovalent Interactions on High-Spin Fe(IV)-Oxido Complexes. J. Am. Chem. Soc. 2020. https://doi.org/10.1021/jacs.0c03085.

(37) Zhang, R.; Warren, J. J. Controlling the Oxygen Reduction Selectivity of Asymmetric Cobalt Porphyrins by Using Local Electrostatic Interactions. J. Am. Chem. Soc. 2020. https://doi.org/10.1021/jacs.0c03861.

(38) Wang, J.; Young, T. A.; Duarte, F.; Lusby, P. J. Synergistic Non-Covalent Catalysis Facilitates Base-Free Michael Addition. J. Am. Chem. Soc. 2020, 59, 17743-17750. https://doi.org/10.1021/jacs.0c08639.

(39) Martin, D. J.; Johnson, S. I.; Mercado, B. Q.; Raugei, S.; Mayer, J. M. Intramolecular Electrostatic Effects on $\mathrm{O}_{2}, \mathrm{CO}_{2}$, and Acetate Binding to a Cationic Iron Porphyrin. Inorg. Chem. 2020, 59, 17402-17414. https://doi.org/10.1021/acs.inorgchem.0c02703.

(40) Deacy, A. C.; Moreby, E.; Phanopoulos, A.; Williams, C. K. Co(III)/Alkali-Metal(I) Heterodinuclear Catalysts for the RingOpening Copolymerization of $\mathrm{CO}_{2}$ and Propylene Oxide. J. Am. Chem. Soc. 2020, 142 (45), 19150-19160. https://doi.org/10.1021/jacs.0c07980.

(41) Weberg, A. B.; McCollom, S. P.; Thierer, L. M.; Gau, M. R.; Carroll, P. J.; Tomson, N. C. Using Internal Electrostatic Fields to Manipulate the Valence Manifolds of Copper Complexes. Chem. Sci. 2021, 12, 4395-4404. https://doi.org/10.1039/D0SC06364A.

(42) Camp, A. M.; Kita, M. R.; Blackburn, P. T.; Dodge, H. M.; Chen, C.-H.; Miller, A. J. M. Selecting Double Bond Positions with a Single Cation-Responsive Iridium Olefin Isomerization Catalyst. J. Am. Chem. Soc. 2021, 143, 2792-2800. https://doi.org/10.1021/jacs.0c11601.

(43) Nie, W.; Tarnopol, D. E.; McCrory, C. C. L. Enhancing a Molecular Electrocatalyst's Activity for CO2 Reduction by Simultaneously Modulating Three Substituent Effects. J. Am. Chem. Soc. 2021 143, 3764-3778. https://doi.org/10.1021/jacs.0c09357.
(44) Martin, D. J.; Mercado, B. Q.; Mayer, J. M. All Four Atropisomers of Iron Tetra(o-N,N,N-Trimethylanilinium)Porphyrin in Both the Ferric and Ferrous States. Inorg. Chem. 2021, 60 (7), 5240-5251. https://doi.org/10.1021/acs.inorgchem.1c00236.

(45) Loewen, N. D.; Pattanayak, S.; Herber, R.; Fettinger, J. C.; Berben, L. A. Quantification of the Electrostatic Effect on Redox Potential by Positive Charges in a Catalyst Microenvironment. J. Phys. Chem. Lett. 2021, 12 (12), 3066-3073. https://doi.org/10.1021/acs.jpclett.1c00406.

(46) Dhar, D.; Yee, G. M.; Tolman, W. B. Effects of Charged Ligand Substituents on the Properties of the Formally Copper(III)-Hydroxide $\left([\mathrm{CuOH}]^{2+}\right)$ Unit. Inorg. Chem. 2018, 57 (16), 9794-9806. https://doi.org/10.1021/acs.inorgchem.8b01529.

(47) Shaik, S.; Danovich, D.; Joy, J.; Wang, Z.; Stuyver, T. Electric-Field Mediated Chemistry: Uncovering and Exploiting the Potential of (Oriented) Electric Fields to Exert Chemical Catalysis and Reaction Control. J. Am. Chem. Soc. 2020, 142 (29), 12551-12562. https://doi.org/10.1021/jacs.0c05128.

(48) Shaik, S.; Mandal, D.; Ramanan, R. Oriented Electric Fields as Future Smart Reagents in Chemistry. Nat. Chem. 2016, 8 (12), 1091-1098. https://doi.org/10.1038/nchem.2651.

(49) Welborn, V. V.; Pestana, L. R.; Head-Gordon, T. Computational Optimization of Electric Fields for Better Catalysis Design. Nat. Catal. 2018, 1 (9), 649-655. https://doi.org/10.1038/s41929-018-0109-2.

(50) Léonard, N.; Dhaoui, R.; Chantarojsiri, T.; Yang, J. Y. Electric Fields in Catalysis: From Enzymes to Molecular Catalysts. ACS Catal. 2021, 11, 10923-10932 https://doi.org/10.1021/acscatal.1c02084.

(51) Kang, K.; Fuller, J.; Reath, A. H.; Ziller, J. W.; Alexandrova, A. N.; Yang, J. Y. Installation of Internal Electric Fields by Non-Redox Active Cations in Transition Metal Complexes. Chem. Sci. 2019, 10 (43), 10135-10142. https://doi.org/10.1039/C9SC02870F.

(52) Chantarojsiri, T.; Reath, A. H.; Yang, J. Y. Cationic Charges Leading to an Inverse Free-Energy Relationship for N-N Bond Formation by MnVI Nitrides. Angew. Chem. Int. Ed. 2018, 57 (43), 14037-14042. https://doi.org/10.1002/anie.201805832.

(53) Eikey, R. A.; Abu-Omar, M. M. Nitrido and Imido Transition Metal Complexes of Groups 6-8. Coord. Chem. Rev. 2003, 243 (1), 83-124. https://doi.org/10.1016/S0010-8545(03)00048-1.

(54) Berry, J. F. Terminal Nitrido and Imido Complexes of the Late Transition Metals. Comments on Inorganic Chemistry 2009, 30 (1-2), 28-66. https://doi.org/10.1080/02603590902768875.

(55) Mehn, M. P.; Peters, J. C. Mid- to High-Valent Imido and Nitrido Complexes of Iron. J. Inorg. Biochem. 2006, 100 (4), 634643. https://doi.org/10.1016/j.jinorgbio.2006.01.023.

(56) Clarke, R. M.; Storr, T. Tuning Electronic Structure To Control Manganese Nitride Activation. J. Am. Chem. Soc. 2016, 138 (47), 15299-15302. https://doi.org/10.1021/jacs.6b09576.

(57) Man, W.-L.; Lam, W. W. Y.; Lau, T.-C. Reactivity of Nitrido Complexes of Ruthenium(VI), Osmium(VI), and Manganese(V) Bearing Schiff Base and Simple Anionic Ligands. Acc. Chem. Res. 2014, 47 (2), 427-439. https://doi.org/10.1021/ar400147y.

(58) Xiang, J.; Jin, X.-X.; Su, Q.-Q.; Cheng, S.-C.; Ko, C.-C.; Man, W.-L.; Xue, M.; Wu, L.; Che, C.-M.; Lau, T.-C. Photochemical Nitrogenation of Alkanes and Arenes by a Strongly Luminescent Osmium(VI) Nitrido Complex. Commun. Chem. 2019, 2 (1), 1-11. https://doi.org/10.1038/s42004-019-0142-3.

(59) Meyer, K.; Bendix, J.; Metzler-Nolte, N.; Weyhermüller, T.; Wieghardt, K. Nitridomanganese(V) and -(VI) Complexes Containing Macrocyclic Amine Ligands. J. Am. Chem. Soc. 1998, 120 (29), 7260-7270. https://doi.org/10.1021/ja980686j.

(60) Keilwerth, M.; Grunwald, L.; Mao, W.; Heinemann, F. W.; Sutter, J.; Bill, E.; Meyer, K. Ligand Tailoring Toward an Air-Stable Iron(V) Nitrido Complex. J. Am. Chem. Soc. 2021, 143 (3), 14581465. https://doi.org/10.1021/jacs.0c11141.

(61) Du Bois, J.; Tomooka, C. S.; Hong, J.; Carreira, E. M. Nitridomanganese $(\mathrm{V})$ Complexes: Design, Preparation, and Use as 
Nitrogen Atom-Transfer Reagents. Acc. Chem. Res. 1997, 30 (9), 364-372. https://doi.org/10.1021/ar960222v.

(62) Chang, C. J.; Low, D. W.; Gray, H. B. Reversible Nitrogen Atom Transfer between Nitridomanganese(V) and Manganese(III) Schiff-Base Complexes. Inorg. Chem. 1997, 36 (3), 270-271. https://doi.org/10.1021/ic961023a.

(63) Golubkov, G.; Gross, Z. Nitrogen Atom Transfer between Manganese Complexes of Salen, Porphyrin, and Corrole and Characterization of a (Nitrido)Manganese(VI) Corrole. J. Am. Chem. Soc. 2005, 127 (10), 3258-3259. https://doi.org/10.1021/ja043683h. (64) Sengupta, D.; Sandoval-Pauker, C.; Schueller, E. C.; Encerrado-Manriquez, A. M.; Metta-Magana, A. J.; Lee, W.-Y.; Seshadri, R.; Pintér, B.; Fortier, S. Isolation of a Bimetallic Cobalt(III) Nitride and Examination of Its Hydrogen Atom Abstraction Chemistry and Reactivity Towards H2. J. Am. Chem. Soc. 2020, 142, 8233-8242. https://doi.org/10.1021/jacs.0c00291.

(65) MacLeod, K. C.; McWilliams, S. F.; Mercado, B. Q.; Holland, P. L. Stepwise N-H Bond Formation from $\mathrm{N}_{2}$-Derived Iron Nitride, Imide and Amide Intermediates to Ammonia. Chem. Sci. 2016, 7 (9), 5736-5746. https://doi.org/10.1039/C6SC00423G.

(66) Du Bois, J.; Hong, J.; Carreira, E. M.; Day, M. W. Nitrogen Transfer from a Nitridomanganese(V) Complex: Amination of Silyl Enol Ethers. J. Am. Chem. Soc. 1996, 118 (4), 915-916. https://doi.org/10.1021/ja953659r.

(67) Ho, C.-M.; Lau, T.-C.; Kwong, H.-L.; Wong, W.-T. Activation of Manganese Nitrido Complexes by Brønsted and Lewis Acids. Crystal Structure and Asymmetric Alkene Aziridination of a Chiral Salen Manganese Nitrido Complex. J. Chem. Soc., Dalton Trans. 1999, No. 15, 2411-2414. https://doi.org/10.1039/A903605I.

(68) Yiu, S.-M.; Lam, W. W. Y.; Ho, C.-M.; Lau, T.-C. Facile N $\cdots \mathrm{N}$ Coupling of Manganese(V) Imido Species. J. Am. Chem. Soc. 2007, 129 (4), 803-809. https://doi.org/10.1021/ja066440t.

(69) Liu, Y.; Lau, T.-C. Activation of Metal Oxo and Nitrido Complexes by Lewis Acids. J. Am. Chem. Soc. 2019, 141 (9), 37553766. https://doi.org/10.1021/jacs.8b13100.

(70) Wang, D.; Loose, F.; Chirik, P. J.; Knowles, R. R. N-H Bond Formation in a Manganese(V) Nitride Yields Ammonia by LightDriven Proton-Coupled Electron Transfer. J. Am. Chem. Soc. 2019, 141 (12), 4795-4799. https://doi.org/10.1021/jacs.8b12957.

(71) Loose, F.; Wang, D.; Tian, L.; Scholes, G. D.; Knowles, R. R.; Chirik, P. J. Evaluation of Excited State Bond Weakening for Ammonia Synthesis from a Manganese Nitride: Stepwise Proton Coupled Electron Transfer Is Preferred over Hydrogen Atom Transfer. Chem. Commun. 2019, 55 (39), 5595-5598. https://doi.org/10.1039/C9CC01046G.

(72) Kim, S.; Zhong, H.; Park, Y.; Loose, F.; Chirik, P. J. Catalytic Hydrogenation of a Manganese(V) Nitride to Ammonia. J. Am. Chem. Soc. 2020, 142 (20), 9518-9524. https://doi.org/10.1021/jacs.0c03346.

(73) Pappas, I.; Chirik, P. J. Catalytic Proton Coupled Electron Transfer from Metal Hydrides to Titanocene Amides, Hydrazides and Imides: Determination of Thermodynamic Parameters Relevant to Nitrogen Fixation. J. Am. Chem. Soc. 2016, 138 (40), 1337913389. https://doi.org/10.1021/jacs.6b08009.

(74) Bezdek, M. J.; Pappas, I.; Chirik, P. J. Determining and Understanding N-H Bond Strengths in Synthetic Nitrogen Fixation Cycles. In Nitrogen Fixation; Nishibayashi, Y., Ed.; Topics in Organometallic Chemistry; Springer International Publishing: Cham, 2017; pp 1-21. https://doi.org/10.1007/3418_2016_8.

(75) Rittle, J.; Peters, J. C. N-H Bond Dissociation Enthalpies and Facile $\mathrm{H}$ Atom Transfers for Early Intermediates of $\mathrm{Fe}-\mathrm{N}_{2}$ and Fe-CN Reductions. J. Am. Chem. Soc. 2017, 139 (8), 3161-3170. https://doi.org/10.1021/jacs.6b12861.

(76) Chalkley, M. J.; Peters, J. C. Relating N-H Bond Strengths to the Overpotential for Catalytic Nitrogen Fixation. European Journal of Inorganic Chemistry 2020, 2020 (15-16), 1353-1357. https://doi.org/10.1002/ejic.202000232.

(77) Johnson, S. I.; Heins, S. P.; Klug, C. M.; Wiedner, E. S.; Bullock, R. M.; Raugei, S. Design and Reactivity of Pentapyridyl Metal
Complexes for Ammonia Oxidation. Chem. Commun. 2019, 55 (35), 5083-5086. https://doi.org/10.1039/C9CC01249D.

(78) Dunn, P. L.; Cook, B. J.; Johnson, S. I.; Appel, A. M.; Bullock, R. M. Oxidation of Ammonia with Molecular Complexes. J. Am. Chem. Soc. 2020, 142 (42), 17845-17858. https://doi.org/10.1021/jacs.0c08269.

(79) Nieto, I.; Ding, F.; Bontchev, R. P.; Wang, H.; Smith, J. M. Thermodynamics of Hydrogen Atom Transfer to a High-Valent Iron Imido Complex. J. Am. Chem. Soc. 2008, 130 (9), 2716-2717. https://doi.org/10.1021/ja0776834.

(80) Reckziegel, A.; Pietzonka, C.; Kraus, F.; Werncke, C. G. C-H Bond Activation by an Imido Cobalt(III) and the Resulting Amido Cobalt(II) Complex. Angew. Chem. Int. Ed. 2020, 59 (22), 85278531. https://doi.org/10.1002/anie.201914718.

(81) Xue, X.-S.; Ji, P.; Zhou, B.; Cheng, J.-P. The Essential Role of Bond Energetics in C-H Activation/Functionalization. Chem. Rev. 2017, 117 (13), 8622-8648. https://doi.org/10.1021/acs.chemrev.6b00664.

(82) Iovan, D. A.; Betley, T. A. Characterization of Iron-Imido Species Relevant for N-Group Transfer Chemistry. J. Am. Chem. Soc. 2016, 138 (6), 1983-1993. https://doi.org/10.1021/jacs.5b12582.

(83) Cowley, R. E.; Holland, P. L. C-H Activation by a Terminal Imidoiron(III) Complex to Form a Cyclopentadienyliron(II) Product. Inorganica Chimica Acta 2011, 369 (1), 40-44. https://doi.org/10.1016/j.ica.2010.11.031.

(84) Ni, C.; Fettinger, J. C.; Power, P. P. Intramolecular C-H Activation by Putative Terminal Two-Coordinate Manganese(III) Imido Intermediates: Hydrogen Abstraction from a Phenyl Group. Organometallics 2010, 29 (1), 269-272. https://doi.org/10.1021/om9007136.

(85) Shannon, R. D. Revised Effective Ionic Radii and Systematic Studies of Interatomic Distances in Halides and Chalcogenides. $\begin{array}{lllll}\text { Acta Cryst A 1976, } 32 \quad \text { (5), } & \text { 751-767. }\end{array}$ https://doi.org/10.1107/S0567739476001551.

(86) Lane, B. C.; McDonald, J. W.; Basolo, F.; Pearson, R. G. Reaction of Azidopentaammineiridium(III) Cation with Acid. Intermediate Formation of Coordinated Nitrene. J. Am. Chem. Soc. 1972, 94 (11), 3786-3793. https://doi.org/10.1021/ja00766a020.

(87) Gafney, H. D.; Reed, J. L.; Basolo, Fred. Photochemical Reaction of the Azidopentaammineiridium(III) Ion. Coordinated Nitrene Intermediate. J. Am. Chem. Soc. 1973, 95 (24), 7998-8005. https://doi.org/10.1021/ja00805a011.

(88) Lutz, C. M.; Wilson, S. R.; Shapley, P. A. The First Imido Complex of Osmium(VI), [CpOs(NH) $\left.\left(\mathrm{CH}_{2} \mathrm{SiMe}_{3}\right)_{2}\right]\left[\mathrm{SO}_{3} \mathrm{CF}_{3}\right]$. Organometallics 2005, 24 (13), 3350-3353. https://doi.org/10.1021/om050084q.

(89) Scheibel, M. G.; Abbenseth, J.; Kinauer, M.; Heinemann, F. W.; Würtele, C.; de Bruin, B.; Schneider, S. Homolytic N-H Activation of Ammonia: Hydrogen Transfer of Parent Iridium Ammine, Amide, Imide, and Nitride Species. Inorg. Chem. 2015, 54 (19), 9290-9302. https://doi.org/10.1021/acs.inorgchem.5b00829.

(90) Kinauer, M.; Diefenbach, M.; Bamberger, H.; Demeshko, S.; Reijerse, E. J.; Volkmann, C.; Würtele, C.; Slageren, J. van; Bruin, B. de; Holthausen, M. C.; Schneider, S. An Iridium(III/IV/V) Redox Series Featuring a Terminal Imido Complex with Triplet Ground State. Chem. Sci. 2018, 9 (18), 4325-4332. https://doi.org/10.1039/C8SC01113C.

(91) Chiu, S.-M.; Wong, T.-W.; Man, W.-L.; Wong, W.-T.; Peng, S.-M.; Lau, T.-C. Facile Nucleophilic Addition to Salophen Coordinated to Nitridoosmium(VI). J. Am. Chem. Soc. 2001, 123 (50), 12720-12721. https://doi.org/10.1021/ja011152c.

(92) Goken, D. M.; Ischay, M. A.; Peters, D. G.; Tomaszewski, J. W.; Karty, J. A.; Reilly, J. P.; Mubarak, M. S. Alkyl Group Incorporation into Nickel Salen during Controlled-Potential Electrolyses in the Presence of Alkyl Halides. J. Electrochem. Soc. 2006, 153 (3), E71. https://doi.org/10.1149/1.2161579.

(93) Cametti, M.; Dalla Cort, A.; Colapietro, M.; Portalone, G.; Russo, L.; Rissanen, K. Evidence of the Facile Hydride and Enolate 
Addition to the Imine Bond of an Aluminum-Salophen Complex. Inorg. Chem. 2007, 46 (22), 9057-9059. https://doi.org/10.1021/ic701521s.

(94) Meot-Ner, M. The Ionic Hydrogen Bond. 2. Intramolecular and Partial Bonds. Protonation of Polyethers, Crown Ethers, and Diketones. J. Am. Chem. Soc. 1983, 105 (15), 4906-4911. https://doi.org/10.1021/ja00353a011.

(95) Sharma, R. B.; Blades, A. T.; Kebarle, P. Protonation of Polyethers, Glymes, and Crown Ethers in the Gas Phase. J. Am. Chem. $\begin{array}{lllll}\text { Soc. } & \mathbf{1 9 8 4}, & 106 & \text { (3), } & \end{array}$ https://doi.org/10.1021/ja00315a007.
(96) Chen, Y.; Rodgers, M. T. Re-Evaluation of the Proton Affinity of 18-Crown-6 Using Competitive Threshold Collision-Induced Dissociation Techniques. Anal. Chem. 2012, 84 (17), 75707577. https://doi.org/10.1021/ac301804j.

(97) Najafian, A.; Cundari, T. R. Effect of Appended S-Block Metal Ion Crown Ethers on Redox Properties and Catalytic Activity of Mn-Nitride Schiff Base Complexes: Methane Activation. Inorg. Chem. 2019, 58 (18), 12254-12263. https://doi.org/10.1021/acs.inorgchem.9b01696. 
Insert Table of Contents artwork here

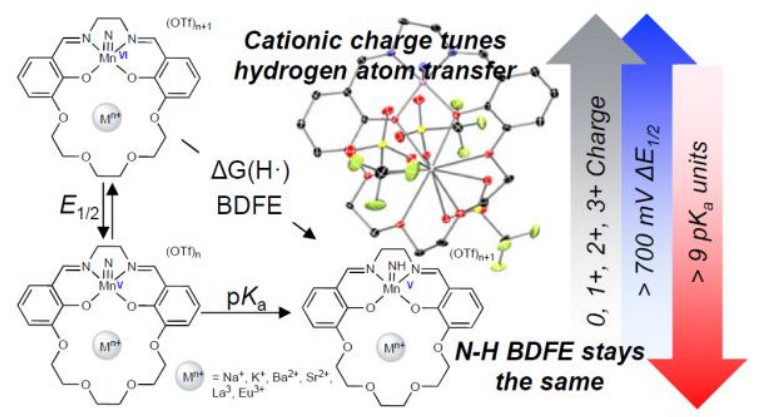

